\title{
EFFECT OF GALVANIC METALLIZATION, PVD PROCESSES AND THERMAL SPRAYING ON FATIGUE PROPERTIES OF PLAIN STRUCTURAL STEELS IN THE ULTRA-HIGH-CYCLE REGIME
}

This work presents information about the influence of Ni and ZnFe galvanic metallization on the fatigue properties of S235JRG2 steel and about the TiN physical vapour deposition and WC thermal spraying on the fatigue properties of S355J0 steel in the ultra-high-cycle region of loading $\left(N=6 \times 10^{6}-10^{10}\right.$ cycles $)$ obtained at high-frequency fatigue testing $\left(f \approx 20 \mathrm{kHz}, T=20 \pm 3{ }^{\circ} \mathrm{C}, R=-1\right)$. Technical coatings are used in order to modify the properties of the surface that is being covered for protection against corrosion but also in order to increase the hardness and resistance to wear. The Ni coating produced by galvanic metallization favourably influences the corrosion resistance but it introduces tensile stresses into the surface layer which act negatively on fatigue properties. No evidence of improving fatigue lifetime was detected in the case of ZnFe, TiN and WC coatings. In all types of coating the fatigue cracks were initiated on the specimen surface e.g. on the coatings surfaces.

Key words: ultra-high cycle fatigue, fatigue limit, galvanic metallization, thermal spraying, PVD processes.

\section{Introduction}

Fatigue limit is one of the most important criteria determining the quality of components and structures. More than $90 \%$ of all fractures are caused by fatigue in service [1,2]. Fatigue lifetime is investigated in the low-cycle region of loading $\left(N_{f}<10^{4}-10^{5}\right.$ cycles), high-cycle region of loading $\left(10^{4}-10^{5}<N_{f}<2 \times 10^{6}-10^{7}\right.$ cycles) and in the ultra-high-cycle region of loading $\left(10^{7}<N_{f}<10^{10}\right.$ cycles). In recent ten years, the ultra-high-cycle region of loading $\left(10^{7}<N_{f}<10^{10}\right.$ cycles) has been investigated intensively by several research teams. The aim of these experimental studies is to increase the fatigue limit, safety and reliability of components and structures [3].

Conventional fatigue testing machines work in the frequency range from $f \approx 10 \mathrm{~Hz}$ to $f \approx 200 \mathrm{~Hz}$. The fatigue tests take a lot of time and they are expensive. The fact that fatigue fractures occur after more than $N_{f}<10^{7}$ cycles of loading motivates the researches to use experimental methods working with a high frequency cyclic loading $(f \approx 20 \mathrm{kHz})[3,4]$.

Fatigue cracks most often occur on the surface. Therefore, surface conditions (microstructure, roughness and residual stresses) can have a significant effect on fatigue resistance resulting in the increase of the fatigue resistance $[5,6]$. Fatigue strength mostly depends on surface roughness. The reducing of the surface roughness about several-tenfold-percent can improve the fatigue limit about $25-100 \%$ [5].
The use of super-high strength steels is growing rapidly, due to their outstanding characteristics. However most steels do have a fundamental disadvantage namely their resistance to corrosion and wear is often insufficient. The application of non-ferrous metal coating is used in engineering praxis with the aim to renovate the components, to increase the resistance to the effect of aggressive environments, to increase the wear resistance and to produce decorative coating. On the other hand, the coatings deposited by galvanic metallization can cause a decrease of the fatigue limit [8].

Galvanic coating deposited on the surface of the metal in order to protect it from corrosion or to increase resistance to abrasion, usually produces in being covered basic material tensile stresses, which reduce the fatigue resistance. During nickel galvanic metallization, but also during other galvanic treatments, the negative impact of treatment increases with an increase of material strength.

Thermal Spraying (THSP) is a group of processes that deposit molten metallic or non-metallic surfacing materials onto a prepared substrate. All thermal spraying processes introduce a feedstock (usually a powder or wire) into a heating device (combustion or electrical). There the material is heated, blended into the heat plume, and sprayed onto a prepared substrate. The molten particles strike the surface, flatten, and form thin platelets that conform and adhere to the substrate and to one another. As they cool, they build up a lamellar structure to form the desired coating.

Physical vapor deposition (PVD) processes are family of coating processes suitable for depositing corrosion protection and other

\footnotetext{
* Frantisek Novy, Rastislav Mintach, Otakar Bokuvka

Department of Materials Science, Faculty of Mechanical Engineering, University of Zilina, Slovakia, E-mail: frantisek.novy@fstroj.uniza.sk
} 
functional layers onto steels. The TiN or TiCN coatings belong to among of PVD coatings. The PVD coatings are produced by BryCoat's proprietary vacuum deposition technologies utilizing cathodic arc coating technology. The advantage of this environmentally friendly technology is that a wide variety of coating materials can be deposited (metals, alloys and compounds).

The aim of this study is to reveal the influence of $\mathrm{Ni}$ and $\mathrm{ZnFe}$ coatings deposited by galvanic metallization on the fatigue behaviour of S235JRG2 steel and influence of TiN coating deposited by PVD process and WC coating deposited by THSP process on the fatigue behaviour of $\mathrm{S} 355 \mathrm{~J} 0$ steel. The results are obtained from fatigue tests in ultra-high-cycle region by the methods of high-frequency loading.

\section{Material and experiments}

The materials used in experimental study were plain low carbon structural steels, namely the S235JRG2 and S355J0 steel. Chemical composition (in wt. \%) and mechanical properties of experimental materials are presented in tables 1 and 2.

Chemical composition and mechanical

Tab. 1. properties of S235JRG2 steel

\begin{tabular}{|c|c|c|c|c|c|c|c|c|}
\hline \multicolumn{10}{|c|}{ Chemical composition [wt. \%] } \\
\hline $\mathrm{C}$ & $\mathrm{Mn}$ & $\mathrm{Si}$ & $\mathrm{S}$ & $\mathrm{P}$ & $\mathrm{Cr}$ & $\mathrm{Ni}$ & $\mathrm{W}$ & $\mathrm{B}$ \\
\hline 0.17 & 0.51 & 0.12 & 0.032 & 0.013 & 0.07 & 0.09 & 0.011 & 0.0001 \\
\hline $\mathrm{Cu}$ & $\mathrm{Mo}$ & $\mathrm{V}$ & $\mathrm{Ti}$ & $\mathrm{Al}$ & $\mathrm{Sn}$ & $\mathrm{N}$ & $\mathrm{Pb}$ & $\mathrm{As}$ \\
\hline 0.27 & 0.01 & 0.001 & 0.001 & 0.003 & 0.001 & 0.0065 & 0.002 & 0.001 \\
\hline \multicolumn{10}{|c|}{$R_{m}[\mathrm{MPa}]$} & \multicolumn{3}{c|}{$A_{5}[\%]$} \\
\hline \multicolumn{1}{|c|}{445.6} & \multicolumn{3}{c|}{30.8} \\
\hline$R_{e}[\mathrm{MPa}]$ & \multicolumn{1}{c|}{ Mechanical properties } \\
\hline
\end{tabular}

Chemical composition and mechanical

Tab. 2 . properties of $\mathrm{S} 355 \mathrm{~J} 0$ steel

\begin{tabular}{|c|c|c|c|c|c|c|c|c|}
\hline \multicolumn{10}{|c|}{ Chemical composition [wt. \%] } \\
\hline $\mathrm{C}$ & $\mathrm{Mn}$ & $\mathrm{Si}$ & $\mathrm{S}$ & $\mathrm{P}$ & $\mathrm{Cr}$ & $\mathrm{Ni}$ & $\mathrm{W}$ & $\mathrm{B}$ \\
\hline 0.17 & 1.35 & 0.34 & 0.019 & 0.016 & 0.014 & 0.017 & 0.009 & 0.0002 \\
\hline $\mathrm{Cu}$ & $\mathrm{Mo}$ & $\mathrm{V}$ & $\mathrm{Ti}$ & $\mathrm{Al}$ & $\mathrm{Sn}$ & $\mathrm{N}$ & $\mathrm{Pb}$ & $\mathrm{As}$ \\
\hline 0.045 & 0.008 & 0.004 & 0.021 & 0.035 & 0.006 & 0.0073 & 0.019 & 0.005 \\
\hline \multicolumn{8}{|c|}{ Mechanical properties } \\
\hline \multicolumn{1}{|c|}{$R_{m}[\mathrm{MPa}]$} & \multicolumn{3}{c|}{$A_{5}[\%]$} \\
\hline \multicolumn{3}{|c|}{557.3} & \multicolumn{3}{c|}{28.6} \\
\hline
\end{tabular}

Six series of specimens were used for the experimental research. The $1^{\text {st }}$ series represents the specimens made from the basic material of S235JRG2 steel without any coating. The $2^{\text {nd }}$ series was made from the same steel with nickel coating. The microstructure of S235JRG2 steel with Ni coating is shown in Fig. 1. The thickness of $\mathrm{Ni}$ layer was about $38 \mu \mathrm{m}$. The $3^{\text {rd }}$ series was prepared also from already mentioned S235JRG2 steel with $\mathrm{ZnFe}$ coating, the microstructure is shown in Fig. 2. The thickness of $\mathrm{ZnFe}$ layer was about $40 \mu \mathrm{m}$. The $4^{\text {th }}$ series represented the specimens made from basic material of S355J0 steel without any coating. The $5^{\text {th }}$ series was prepared from the same steel with TiN PVD-coating (Fig. 3) and in $6^{\text {th }}$ series specimens with WC thermal sprayed coating were used (Fig. 4). The thickness of TiN layer was about $4 \mu \mathrm{m}$ and WC layer about $100 \mu \mathrm{m}$.

A light metallographic microscope AXIO Imager A1m was used for metallography analysis. Both experimental steels have ferritic-perlitic fine-grained microstructure. The S355J0 steel was delivered after normalization. The fractography analyses of fracture surfaces were carried out by using scanning electron microscope TESLA BS 340 [9], [10].

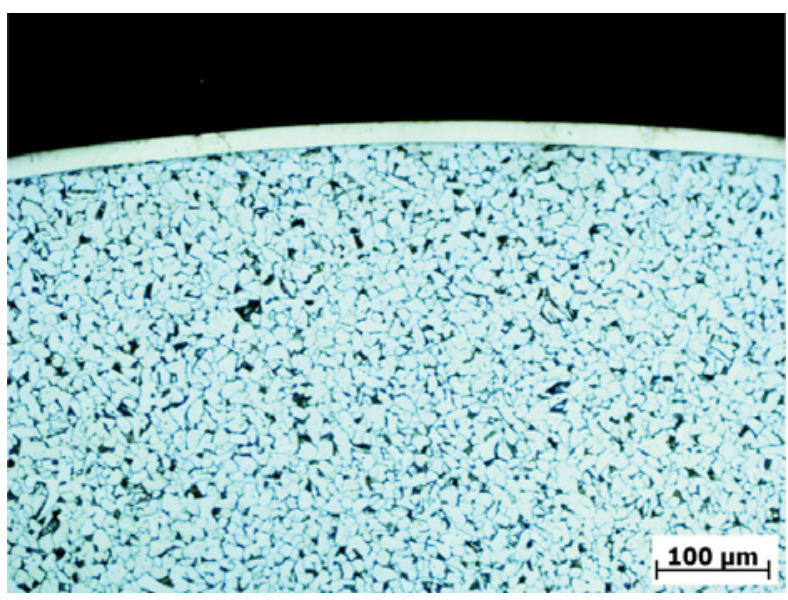

Fig. 1 Microstructure of S235JRG2 steel with Ni coating

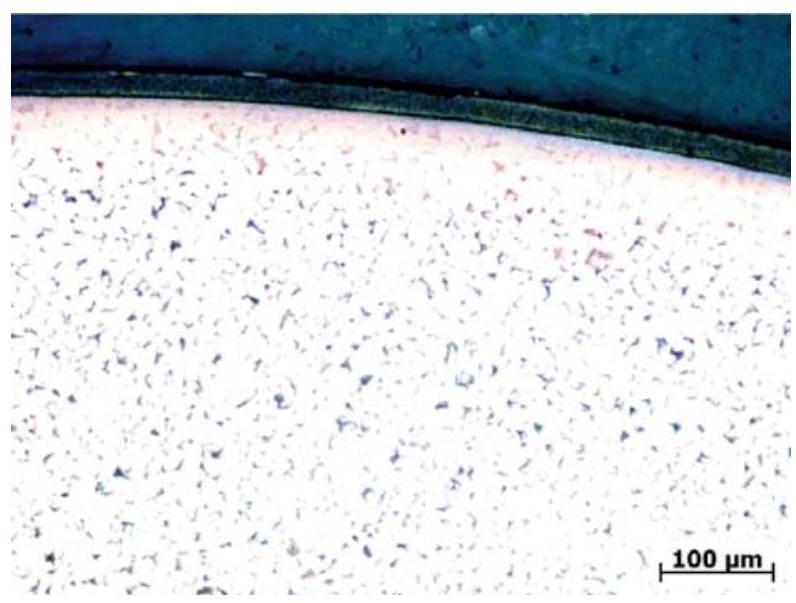

Fig. 2 Microstructure of S235JRG2 steel with ZnFe coating

An ultrasonic resonant high-frequency fatigue machine KAUP$\mathrm{ZU}$ was used for fatigue tests. The experiments were carried out at sinusoidal tension-compression loading with the frequency of $20 \mathrm{kHz}$. The stress ratio of $R=-1$ was used. The smooth fatigue 


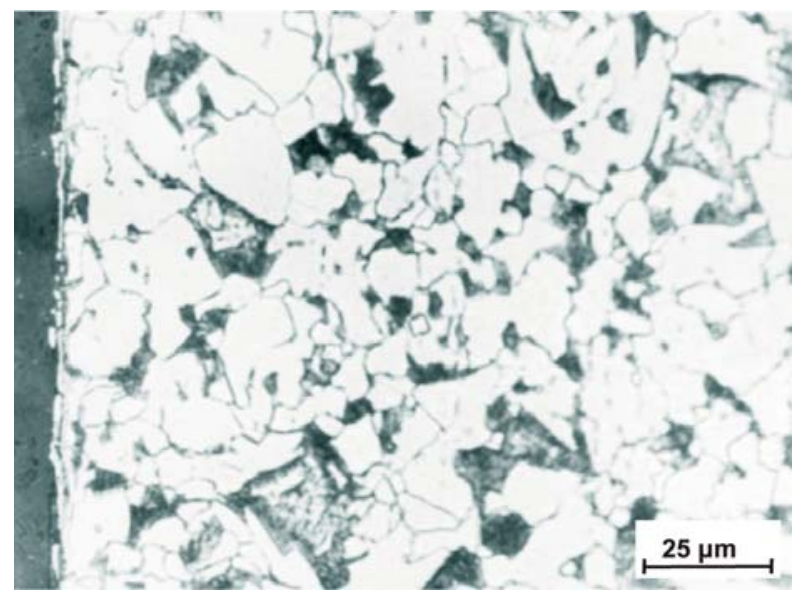

Fig. 3 Microstructure of S355J0 steel with TiN coating

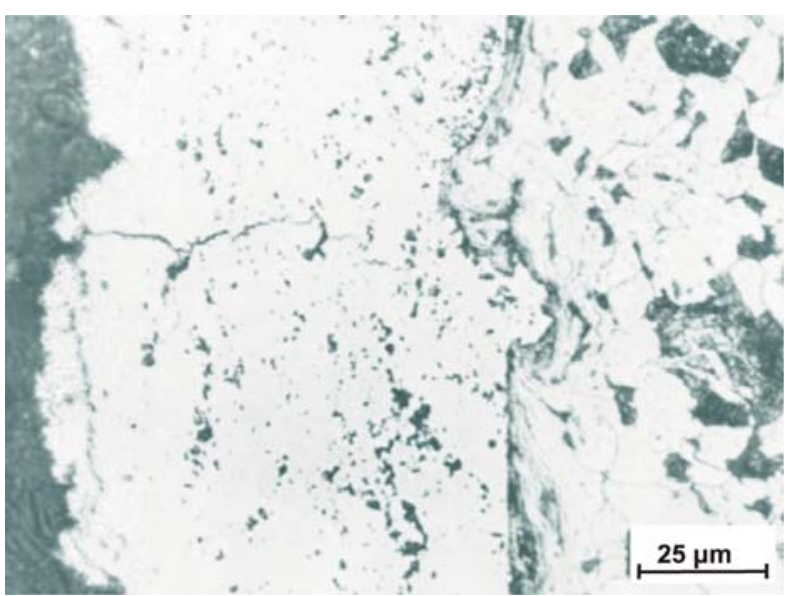

Fig. 4 Microstructure of S355J0 steel with WC coating

specimens with gauge diameter of $4 \mathrm{~mm}$, were prepared according to Puskar's recommendations, so that they fulfil resonance conditions at high frequency fatigue loading. Used testing methods and procedures are described and explained in more detail in [4]. Fatigue tests were performed at the ambient temperature $\left(T=20 \pm 3{ }^{\circ} \mathrm{C}\right)$. Specimens were cooled by distilled water with an anticorrosive inhibitor. The whole specimens were grounded and polished for elimination of surface roughness before the application of coatings.

\section{Results and discussion}

Results of high frequency fatigue tests obtained on S235JRG2 steel at uniaxial cyclic push-pull loading in the region from $N_{f} \approx$ $\approx 2.5 \times 10^{6}$ cycles to $N_{f} \approx 3 \times 10^{10}$ cycles are presented in the form of S-N curve (dependence of stress amplitude vs. number of cycles) in Fig. 5. The stress amplitude was chosen from the interval $\sigma_{a}=(260-160 \mathrm{MPa})$. There are represented the fatigue results for specimens from basic material, specimens with $\mathrm{Ni}$ and $\mathrm{ZnFe}$ coatings. All the specimens were cycled till fracture. It can be seen that the experimental fatigue lifetime continuously decreases from high-cycle to ultra-high-cycle region for all three series of specimens. Decreasing stress amplitude leads to increase of number of cycles to fracture. The fatigue lifetime of basic material is essentially higher than that for the material with $\mathrm{Ni}$ coating in the region of higher stress amplitude $\left(\sigma_{a}>200 \mathrm{MPa}\right)$ and lower number of cycles to fracture $\left(N_{f}<10^{9}\right.$ cycles $)$. In this region of stress amplitude the steel with $\mathrm{ZnFe}$ coating has approximately the same values of fatigue lifetime as the basic steel. In the ultra-high-cycle region any clear distinction of fatigue lifetime wasn't detected among basic material and steel with $\mathrm{Ni}$ and $\mathrm{ZnFe}$ coatings.

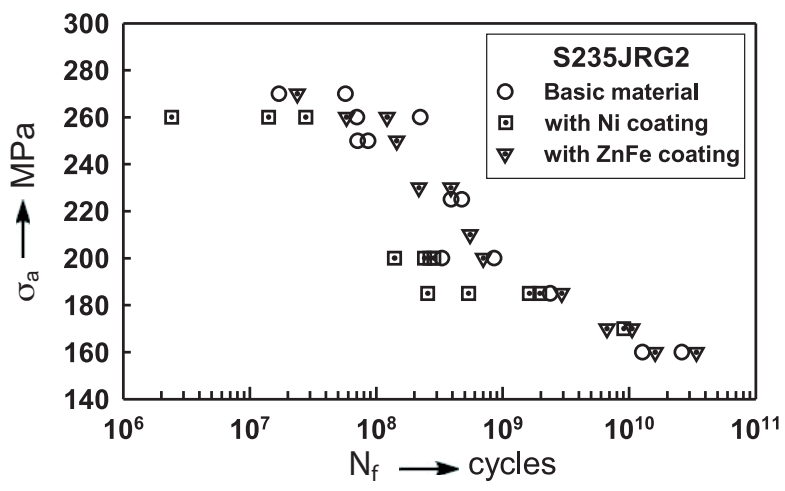

Fig. 5 The S-N dependence of the S235JRG2 steel

Three different types of coating fractures were observed in the case of steel with Ni coating. The fatigue cracks were initiated either from the specimen surface (e.g. from the surface of Ni coating) or from the interface between base material and Ni coating. In the region of high stress amplitude and low cycle region the granular fracture of the coating was detected. The example for the specimen subjected to stress amplitude $\sigma_{a}=260 \mathrm{MPa}$ is shown in Fig. 6 . The fatigue lifetime was about $N_{f}=1.41 \times 10^{7}$ cycles. The thickness of Ni layer was $38 \mu \mathrm{m}$. The decohesion between the base material and coating (marked with arrows) was often observed.

With decreasing stress amplitude the character of coating damage was changed. The example of fracture surface of the $\mathrm{Ni}$ base layer in the case of specimen subjected to stress amplitude $\sigma_{a}=200 \mathrm{MPa}$ is shown in Fig. 7. Fatigue lifetime was $N_{f}=$ $=2.66 \times 10^{8}$ cycles. It can be seen that the fatigue fracture of the coating has fine grained character. In the case of stress amplitude lower than $185 \mathrm{MPa}$ the fatigue striations were detected on the fracture surface of Ni coating. The detail of fatigue striation in the Ni coating is shown in Fig. 8 for the specimen subjected to stress amplitude of $\sigma_{a}=185 \mathrm{MPa}, N_{f}=1.62 \times 10^{9}$ cycles. This indicates the localization of high plastic deformation during the fatigue crack growth. The fatigue fracture areas alternated the areas with brittle fracture in the Ni coating. The brittle character of Ni coating and change of fracture mode with decreasing stress amplitude can be the reasons of premature degradation of tested steel with $\mathrm{Ni}$ coating. 


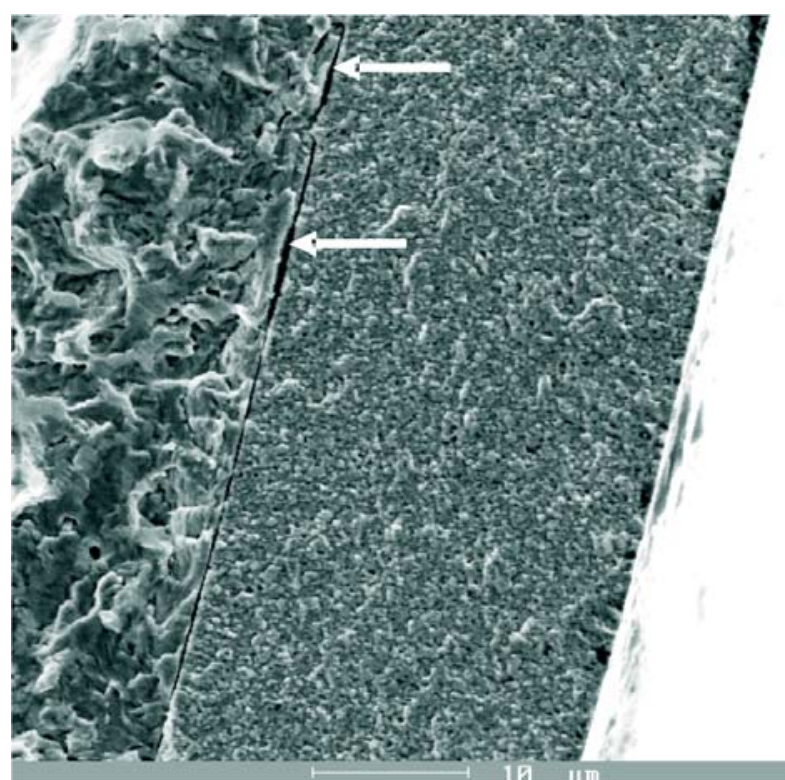

Fig. 6 Granular fracture surface of Ni coating on the S235JRG2 steel, $\sigma_{a}=260 \mathrm{MPa}, N_{f}=1.41 \times 10^{7}$ cycles

In the case of FeZn coating the fatigue cracks were initiated from the coating surface and propagated through this layer to the specimen interior. In whole range of stress amplitudes the ductile damage of FeZn coating was detected. No changes of fracture mode were detected with decreasing stress amplitude. This led to similar fatigue lifetime in the whole range of cyclic loading as in the case of basic material without coating. The example of fracture surface of FeZn coating is shown in Fig. 9 for the specimen subjected to stress amplitude of $260 \mathrm{MPa}$ with fatigue lifetime $N_{f}=$

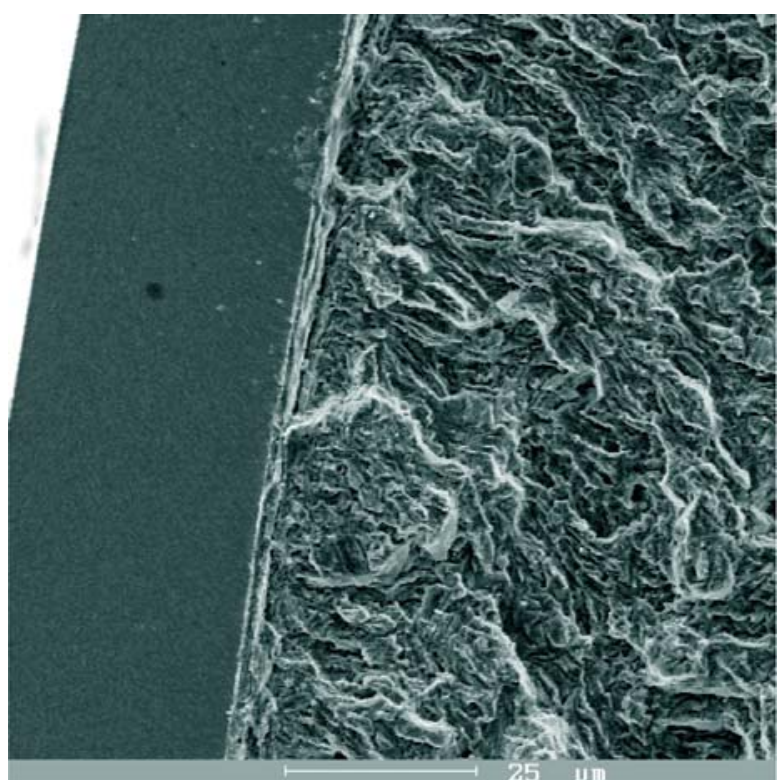

Fig. 7 Fine grain fracture surface of Ni coating, $\sigma_{a}=200 \mathrm{MPa}$, $N_{f}=2.66 \times 10^{8}$ cycles

$=5.82 \times 10^{7}$ cycles. The exact fatigue crack initiation site couldn't be relived because of ductile fracture of FeZn coating which had granular character.

Results of high frequency fatigue tests obtained on S355J0 steel are presented also in the form of S-N curve (Fig. 10). The fatigue data for basic material and for steel with TiN and WC coatings are mutually compared. The S-N curve continuously decreases from high-cycle to ultra-high-cycle region. It can be seen that all

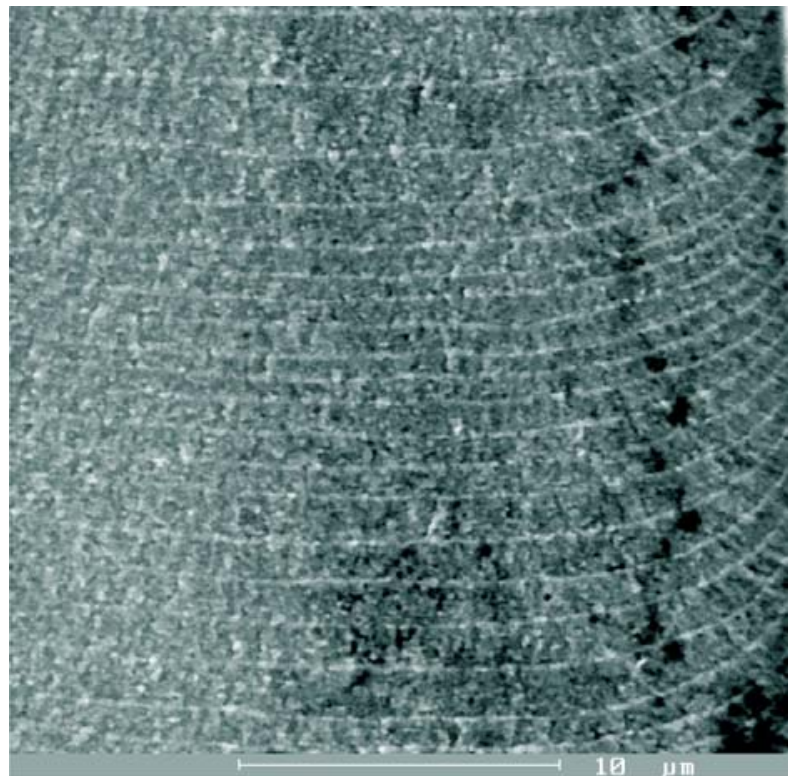

Fig. 8 Detail of fatigue striations on the surface of Ni coating, $\sigma_{a}=185 \mathrm{MPa}, N_{f}=1.62 \times 10^{9}$ cycles

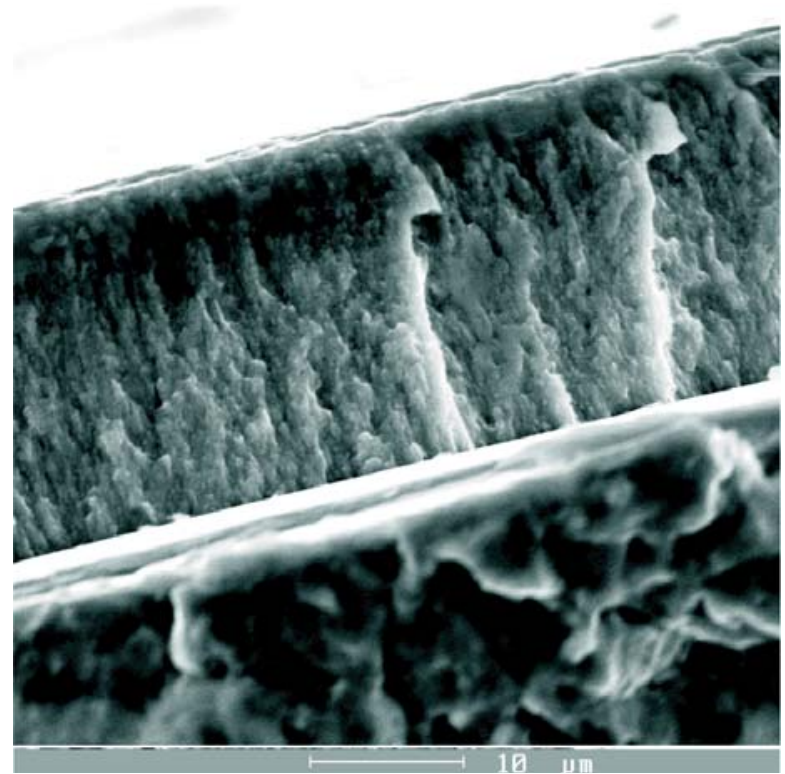

Fig. 9 Ductile damage of FeZn coating, $\sigma_{a}=260 \mathrm{MPa}, N_{f}=5.82 \times 10^{7}$ cycles 


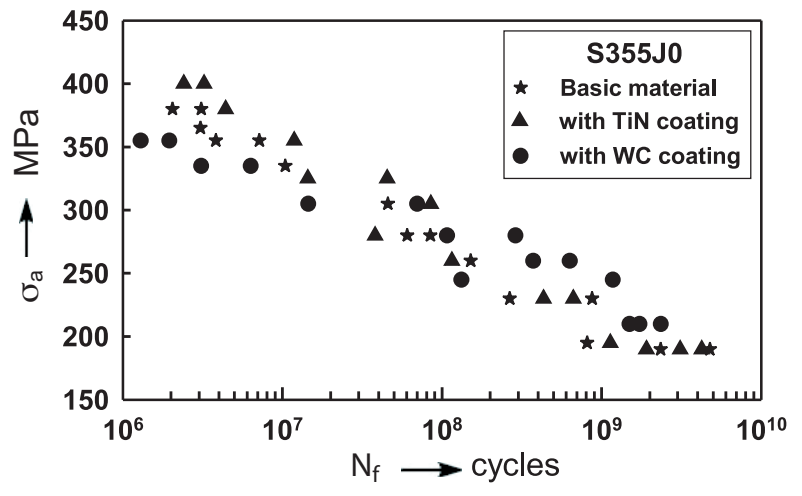

Fig. 10 The $S-N$ dependence of the S355J0 steel

experimental data (for basic steel and steel with coatings also) mutually differ less than $50 \mathrm{MPa}$ in the whole range of stress amplitude. In the region of high stress amplitude the steel with TiN coating has higher fatigue lifetime than that for basic steel and steel with WC coating. With decrease of the stress amplitude this behavior was changed and the lifetime of steel with TiN coating is lower than in the case of basic steel and steel with WC coating. It can be probably explained by high scatter of data due to pores and inhomogenities found in the WC coating. It is hard to say whether or not the TiN and WC coating have positive or negative influence on the fatigue lifetime when compared to basic steel. The fatigue fracture character of the specimens with TiN and WC coatings can be seen in Figs. 11-14.

\section{Conclusions}

On the basis of this study and the obtained experimental results it was determined that:

- Galvanic Ni coating causes a reduction of fatigue lifetime of the S235JRG2 steel in the low-cycle fatigue region. On the other hand, in the high and ultra-high-cycle fatigue area the influence of galvanic metallization by $\mathrm{Ni}$ on the fatigue lifetime is not as strong as in low-cycle fatigue area.

- Galvanic $\mathrm{ZnFe}$ coating doesn't influence the fatigue lifetime of the S235JRG2 steel in the whole range of cyclic loading.

- The TiN coating deposited by PVD process and WC coating deposited by thermal spraying have only weak influence of the fatigue lifetime of S355J0 steel.

\section{Acknowledgements}

This research has been supported by the Scientific Grant Agency of the Ministry of Education of the Slovak Republic and Slovak Academy of Sciences, grants No. 1/0193/10 and No. 1/0262/10.

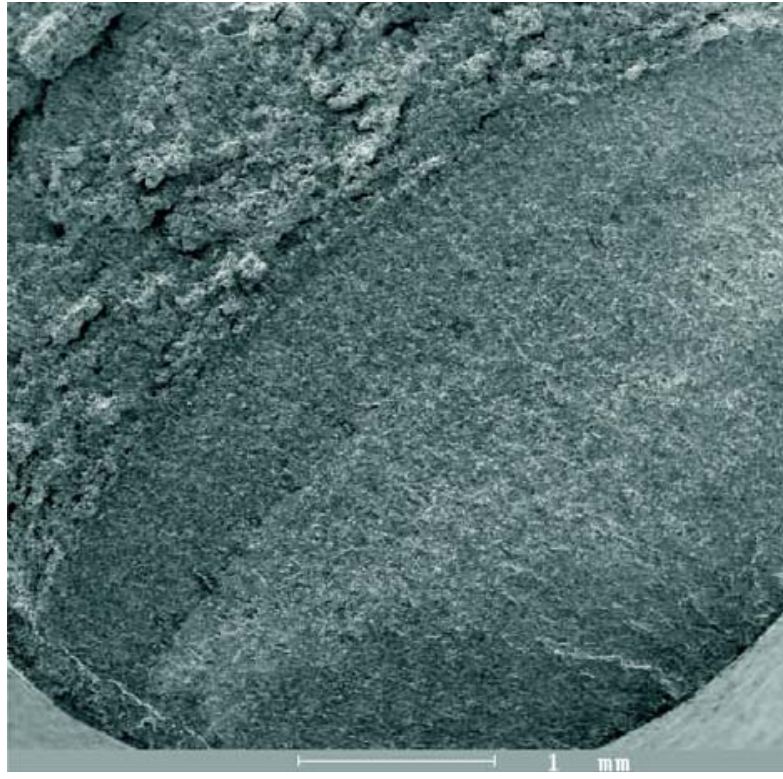

Fig. 11 Fracture surface of S355J0 steel with TiN coating, $\sigma_{a}=310 \mathrm{MPa}, N_{f}=9.1 \times 10^{7}$ cycles

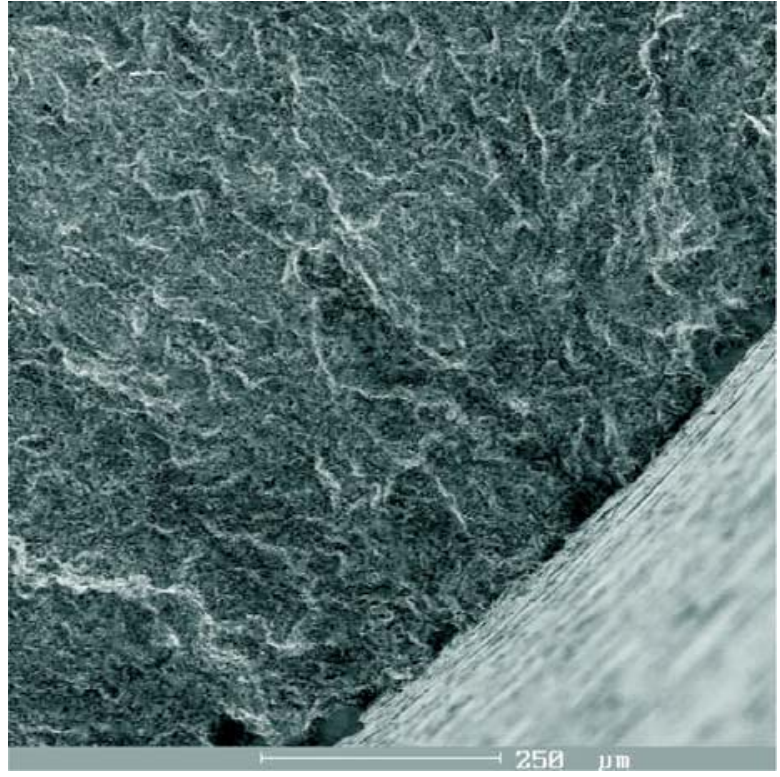

Fig. 12 Detail of fatigue crack initiation site on TiN coating, $\sigma_{a}=310 \mathrm{MPa}, N_{f}=9.1 \times 10^{7}$ cycles 


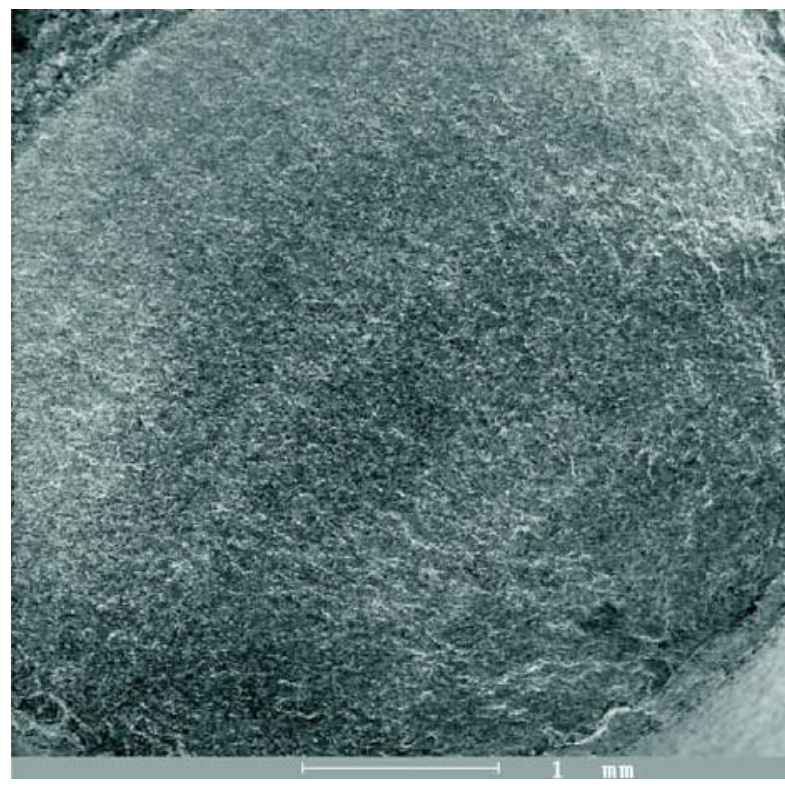

Fig. 13 Fracture surface of S355J0 steel with WC coating, $\sigma_{a}=310 \mathrm{MPa}, N_{f}=1.5 \times 10^{7}$ cycles

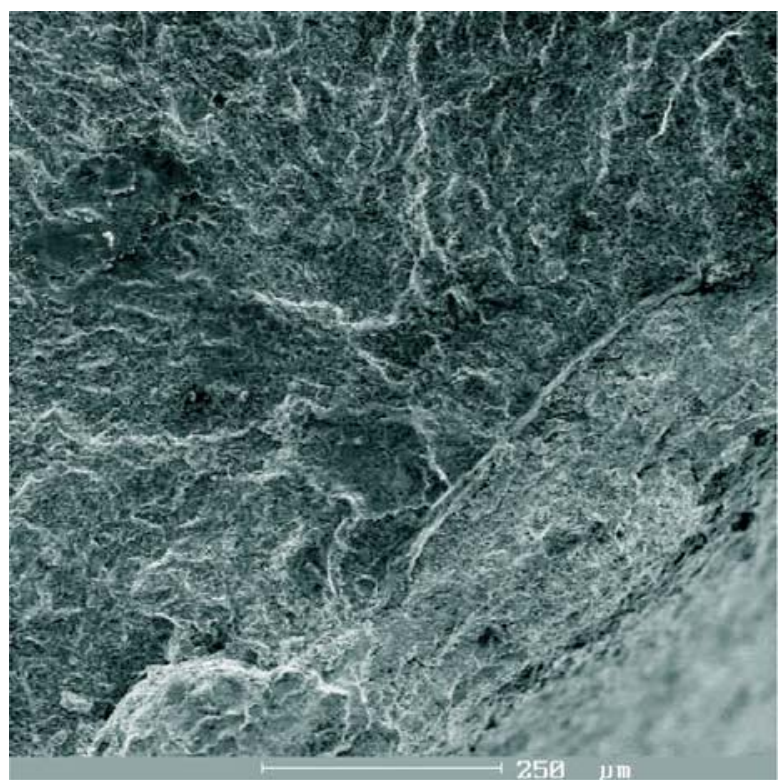

Fig. 14 Detail of fatigue crack initiation site on WC coating, $\sigma_{a}=310 \mathrm{MPa}, N_{f}=1.5 \times 10^{7}$ cycles

\section{References}

[1] BIDULSKY, R., ACTIS-GRANDE, M., KABATOVA, M., BIDULSKA, J.: Journal of Materials Science \& Technology. Vol. 25, No. 5, 2009, pp. 607-610.

[2] BOKUVKA, O., NICOLETTO, G., KUNZ, L., PALCEK, P., CHALUPOVA, M.: Low and High Frequency Fatigue Testing. EDIS, University of Zilina, 2002.

[3] BATHIAS, C., PARIS, P. C.: Gigacycle Fatigue in Mechanical Practice. M. Dekker : New York 2005.

[4] PUSKAR, A.: The Use of High - Intensity Ultrasonic. Elsevier, Amsterdam : Oxford : New York 1982.

[5] MURAKAMI, Y.: Metal Fatigue: Effects of Small Defects and Nonmetalic Inclusions. First edition, Elsevier Science, 2002.

[6] NOVY, F., KOPAS, P., BOKUVKA, O., CHALUPOVA, M.: Materials Engineering, Vol. 10, No. 3, 2003, pp. 67-70.

[7] BURAKOWSKI, T., WIERZCHON, T.: Surface Engineering of Metals. WNT Warsaw 1995.

[8] DORAZIL, E., HRSTKA, J.: Strojirenske materialy a povrchove upravy [Engineering Materials and Surface Treatments]. VUT Brno, 1985 (in Czech).

[9] PALCEK, P., CHALUPOVA, M.: Materials Engineering. Vol. 9, No. 2, 2002, pp. 57-66.

[10] PALCEK, P., CHALUPOVA, M.: Predikcia zivotnosti strojovych zariadeni [Endurance Prediction of Machine Devices]. EDIS ZU Zilina, 2000 (in Slovak). 